\title{
Dinâmicas socioeconômicas e produtivas no Rio Grande do Sul: situação das Microrregiões Campanha Meridional e Serra do Sudeste
}

\author{
Socio-economic and productive dynamics in Rio Grande do Sul: situation of \\ Microregions South Campaign and Serra do Sudeste
}

\author{
Alessandra $\operatorname{Matte}^{1}\left({ }^{*}\right)$ \\ Paulo Dabdab Waquil ${ }^{2}$
}

\section{Resumo}

O objetivo deste artigo é analisar as transformações socioeconômicas e produtivas que têm ocorrido nas microrregiões Campanha Meridional e Serra do Sudeste, localizadas no extremo sul do Rio Grande do Sul. Para tanto, o contexto empírico do estudo toma como referência os municípios de Bagé e Dom Pedrito localizados na microrregião Campanha Meridional, e Piratini e Pinheiro Machado, situados na microrregião Serra do Sudeste. Nos aspectos produtivos, observa-se que a pecuária de corte tem cedido espaço para outras atividades produtivas, particularmente para as lavouras agrícolas e a silvicultura. Alguns dos impactos decorrentes dessas transformações apontam para consequências como a elevação do preço da terra, redução de áreas destinadas à pecuária sobre campos naturais, pressão à modernização da atividade, supressão do bioma Pampa e perda da biodiversidade, consequências essas potencialmente capazes de gerar diferentes situações de vulnerabilidade para a atividade pecuária. Os impactos sociais da presença dessas atividades merecem ser investigados e, a longo prazo, novos estudos devem ser realizados para verificar quais aspectos têm sido modificados juntamente com essas novas atividades.

Palavras-chave: desenvolvimento rural, desigualdades socioeconômicas, diversidade produtiva, pecuária.

\section{Abstract}

This article aims to analyze the socioeconomic and productive transformations that have occurred in the regions Campaha Meridional and Serra do Sudeste, located in southern Rio Grande do Sul. Therefore, the empirical context of the study makes reference to the municipalities of Bagé and Dom Pedrito located in the micro Campaha Meridional, and Piratini and Pinheiro Machado located in the micro region Serra do Sudeste. In the productive aspects, it is observed that the beef cattle industry has given way to other

1 Dra.; Desenvolvimento Rural; Universidade Federal do Rio Grande do Sul, UFRGS, Brasil. Pesquisadora da Aberystwyth University, ABER, Gales; Endereço: Universidade Federal do Rio Grande do Sul, Faculdade de Ciências Econômicas, Programa de Pós-Graduação em Desenvolvimento Rural. Av. João Pessoa, 31 Centro, 90040000 - Porto Alegre, RS Brasil; E-mail: alessandramatte@yahoo.com.br

2 Dr.; Economia Agrícola; University of Wisconsin - Madison, WISC, Estados Unidos; professor titular do Departamento de Economia e Relações Internacionais (DERI) da Universidade Federal do Rio Grande do Sul (UFRGS); Endereço: Universidade Federal do Rio Grande do Sul, Faculdade de Ciências Econômicas, Departamento de Ciências Econômicas, Av. João Pessoa, 31 Centro, 90040000 - Porto Alegre, RS - Brasil; E-mail: waquil@ufrgs.br

\begin{tabular}{llllll}
\hline Ambiência & Guarapuava (PR) & v.14 n.1 & p.101-118 & Jan/Abr 2018 & ISSN $1808-0251$
\end{tabular}


productive activities, particularly for agricultural crops and forestry. Some of the impacts of these changes point to consequences such as rising land prices, reduction of areas for livestock on natural fields, pressure to modernize the activity, suppression of the Pampa biome, and loss of biodiversity, consequences of these potentially capable of generating different situations vulnerability to livestock activity. The social impacts of the presence of these activities deserve to be investigated and, in the long run, further studies should be conducted to ascertain which aspects have been modified with these new activities.

Key words: rural development, socioeconomic inequalities, productive diversity, livestock.

\section{Introdução}

Este artigo analisa as transformações socioeconômicas e produtivas que têm ocorrido no extremo sul do Rio Grande do Sul. O contexto empírico do estudo toma como referência os municípios de Bagé e Dom Pedrito localizados na microrregião Campanha Meridional, e Piratini e Pinheiro Machado situados na microrregião Serra do Sudeste. De acordo com a Fundação de Economia e Estatística (FEE) do Rio Grande do Sul, uma microrregião é definida por meio de especificidades quanto à organização do espaço, como, por exemplo, a estrutura de produção, a agropecuária, o industrial, o extrativismo mineral ou a pesca. A organização das microrregiões considera a produção propriamente dita, distribuição, troca e consumo, incluindo atividades urbanas e rurais (FEE, 2008).

A formação cultural, social, econômica dessas microrregiões foi forjada a partir da introdução de bovinos de corte no período colonial no século XVII, e desde então, a atividade da pecuária de corte extensiva permanece sendo uma das principais atividades produtivas desse espaço. No entanto, em período mais recente, as dinâmicas de desenvolvimento nessas microrregiões vêm sendo alteradas, verificando-se mudanças envolvendo estratégias produtivas, as quais têm reconfigurado as dinâmicas socioeconômicas, fundiárias e ambientais.

Nesse sentido, têm-se assistido atualmente não somente a permanência das tentativas históricas de modernizar os processos produtivos da atividade tradicional pastoril, mas as constantes tentativas de inovação produtiva e tecnológica de novas atividades, como vêm ocorrendo no caso dos empreendimentos de silvicultura ${ }^{1}$ e os cultivos agrícolas em grande escala. Nessas condições, os campos naturais da região sul vêm cedendo espaço e sendo substituídos de forma intensa e imediata pelo monocultivo das lavouras de soja e de árvores exóticas ${ }^{2}$ (BERTÊ, 2004; OVERBECK et al., 2009; MORALES GROSSKOPF et al., 2011). Assim, este artigo tem como objetivo analisar as transformações socioeconômicas e produtivas que têm ocorrido nas microrregiões Campanha Meridional e Serra do Sudeste, localizadas no extremo sul do Rio Grande do Sul.

O artigo está organizado em quatro seções, além dessa introdução. A primeira seção ilustra aspectos da formação histórica dos municípios estudados, de maneira a auxiliar na compreensão das transformações recentes. Na segunda seção são apresentados e analisados aspectos relacionados

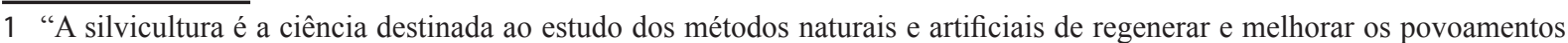
florestais, visando às necessidades do mercado e à manutenção, ao aproveitamento e ao uso racional das florestas (nativas ou comerciais)" (PEREIRA, 2010, p. 89).

2 As espécies exóticas que têm sido utilizadas para os plantios comerciais são Pinus spp., Eucalyptus spp. e Acacia spp., principalmente.
} 
às mudanças na dinâmica populacional, socioeconômicas e da situação fundiária dos municípios estudados. $\mathrm{Na}$ terceira seção a análise recai sobre os processos envolvendo as transformações produtivas dos municípios. Por fim, na quarta e última seção, são apresentadas algumas considerações finais que apontam para uma síntese dos principais resultados, sugerindo novos estudos a partir dos dados aqui analisados.

\section{Evolução dos aspectos históricos nas microrregiões Campanha Meridional e Serra do Sudeste}

O Sul do Rio Grande do Sul, incluindo as microrregiões estudadas, tem marcantes características históricas relacionadas à atividade pecuária, propiciadas pela forma de ocupação e pela presença de pastagens naturais (SUERTEGARAY, PIRES DA SILVA, 2009). A região sul foi inicialmente ocupada por índios que viviam da caça e da pesca, alimentando-se de animais de pequeno porte como veados, emas, capivaras, antas e pequenos roedores (BEHLING et al., 2009). A partir do século XVI, os jesuítas espanhóis iniciam várias tentativas de ocupação do território gaúcho, trazendo consigo significativo número de cabeças de gado direcionada a sua própria alimentação e daquele povo que ali se encontrava (PESAVENTO, 1985). A missão dos jesuítas era cristianizar, civilizar e incorporar à coroa espanhola os índios que habitavam aquele território.

Ao longo do século XVII ocorrem enfrentamentos entre jesuítas e portugueses, pela ocupação do território gaúcho. Resultado disso foi à escravidão de muitos índios, lavados ao estado de São Paulo para trabalhar na agricultura, enquanto alguns poucos conseguiram fugir. Essa situação levou ao abandono de inúmeras cabeças de gado, que se propagou pelos campos do bioma Pampa e ali se reproduziram de forma considerável. O Bioma Pampa é único no mundo, abrangendo parte significativa do Rio Grande do Sul, Uruguai e Argentina, sendo esse bioma reconhecido como um grande produtor de carnes, provenientes de seus campos naturais. Ainda não se tem certeza do total de espécies animais e vegetais presentes na composição do bioma, porém há um consenso quanto a sua vasta diversidade de fauna e flora. Bilenca e Miñarro (2004), estimam que haja aproximadamente 3.000 plantas vasculares, 385 espécies de pássaros e 90 mamíferos terrestres, sobre a área que abrange o bioma Pampa.

De acordo com Pesavento (1985) e Wiederspahn (1979) os índios que fugiram da escravidão buscaram refugio em regiões de difícil acesso, as quais representavam pouco interesse dos europeus, vindo a ocupar a região compreendida como Serra do Sudeste. No entanto, a ocupação desse espaço ainda não era significativa, o que levaria, mais tarde, a vinda de agricultores portugueses para produzirem nessas terras. Assim, por volta de 1750 são trazidos de Portugal casais açorianos, formando as primeiras vilas e povoados nessas áreas. A chegada desses casais à região vem no intuito de ocupar as áreas mais dobradas (MORAES, 1959; WIEDERSPAHN, 1979; PESAVENTO, 1985). Esses casais açorianos praticavam a agricultura de subsistência, principalmente.

Com isso, a reprodução do rebanho bovino é favorecida pela ausência de caça e pela "exuberância das pastagens rio-grandenses, condições mais que favoráveis à sua [bovinos] sobrevivência e proliferação" (REVERBEL, 1986, p. 22), formando, assim, uma imensa reserva de gado. Na mesma medida em que o tamanho do rebanho de gado solto, agora selvagem, aumentava, crescia também o interesse por parte da coroa portuguesa em comercializá-los, despertando um olhar sobre o potencial econômico desses animais. A partir disso, tem início à caça desse gado xucro (também chamado de "chimarrão"), extraindo somente o seu couro e deixando a carne no campo para outros animais consumirem (PESAVENTO, 1985; MAESTRI, 2006). Nessa ocasião, o que 
atribuía valor a esses animais era o couro, utilizado e comercializado pelos índios e portugueses, sendo esse período então denominado de "idade do couro" (REVERBEL, 1986, p. 19).

Ao final do século XVII a conjuntura nacional sofre transformações por conta, principalmente, do surgimento de minas no centro do país e da decadência do açúcar, despertando um novo olhar sobre o sul o país (PESAVENTO, 1985; REVERBEL, 1986). O interesse, então, sobrecai no gado xucro disponível no sul, que, a partir desse momento, passa a ser levado para o centro do país para a região de Minas Gerais, com o intuito de atender a demanda por alimento para os escravos e para tração. Segundo Reverbel (1986, p. 69), o quadro geral do Rio Grande do Sul era de "pastagens abundantes e enormes rebanhos sem dono", em que a apreensão do gado ocorria sem controle algum e sem preocupações acerca de sua manutenção e reprodução.

Assim, verifica-se um novo direcionamento no uso do gado, influenciado por uma nova conjuntura nacional, caracterizado pelo povoamento do território, subdivisão dos campos e intensificação da exploração rural, dando início às estâncias de criação extensiva de gado. Desse modo, com o objetivo de ocupar o território gaúcho, tentando impedir a invasão dos espanhóis e, sobretudo, domesticar o gado selvagem que poderia contribuir com a economia da nação, tem início a distribuição de sesmarias por parte da coroa portuguesa, surgindo então às estâncias de criação de gado (PESAVENTO, 1985; REVERBEL, 1986). De acordo com Pesavento (1985, p. 15), "as sesmarias eram terras devolutas, medindo em regra três léguas por uma légua (cerca de 13.000 hectares)". Também fez parte desse cenário a presença do escravo negro, encontrado como mão de obra (peão) nas estâncias de criação de gado (MORAES, 1959; MAESTRI, 2006). Ressalta-se que juntamente com o rebanho bovino desenvolvia-se a ovinocultura, utilizada principalmente para o autoconsumo. O surgimento das estâncias de criação de gado permitiu a mercantilização da pecuária por meio da comercialização do charque, atribuindo um novo valor à carne (PESAVENTO, 1985). As charqueadas consistiam de uma transformação artesanal da carne de gado para uma carne seca, sendo utilizada na alimentação de escravos para todo o país, tendo seu início por volta de 1780 (IBGE, 2010).

Ao fim da concessão de sesmarias, os estancieiros distribuem alguns lotes de suas áreas de terra às famílias que estavam alocadas no estabelecimento. Concomitante a esse pequeno desmembramento das estâncias, ocorre a ocupação de áreas irregulares como na Serra do Sudeste, principalmente por forasteiros, famílias de pequenos pecuaristas que foram expulsos das estâncias, açorianos e negros agora livres. Com o passar do tempo, o número e a força desses pequenos pecuaristas mestiçados tomou proporções significativas. Percebendo que estes praticavam uma pecuária com baixo ou nenhum investimento, com uso basicamente da mão de obra familiar e sem estarem diretamente dependentes do mercado, esses criadores passam a ser denominados de "pecuaristas familiares." (RIBEIRO, 2009; NESKE, 2009).

Assim, a $1^{\circ}$ Lei de Terras de 1850 dá início a um novo ciclo no que concerne a ocupação de áreas de terra. A atividade pecuária passa, então, a dividir espaço com o cultivo do trigo e com as atividades de subsistência, mas permanece sendo um motor pujante da região sul do estado do Rio Grande do Sul. Em meados do século XX chega ao fim às charqueadas, marcada por melhorias no manejo dos animais, como o cercamento dos campos, e no processamento da carne por meio da implantação de frigoríficos. O fim das charqueadas é resultado de um conjunto de acontecimentos como as altas tarifas sobre o sal e a entrada e concorrência de produto platino (vindo do Uruguai), resultando em queda dos preços e do consumo. De maneira geral, as charqueadas contribuíram, em um primeiro momento, para o crescimento econômico bem como para a abertura e desenvolvimento de novos setores. A decadência do charque dá abertura à criação de frigoríficos, representando importante alavanca para a reestruturação e desenvolvimento da pecuária ao possibilitar a exportação de carne congelada. 
De maneira geral, a pecuária de corte extensiva é a atividade produtiva predominante desde o período de colonização no século XVIII, sendo exercida sobre áreas de campos naturais. No entanto, a estabilização e consolidação da pecuária foi possível mediante, principalmente, às extensas áreas cobertas por pastagem nativa, característica do Bioma Pampa. Esse bioma abrange significativa porção do estado do Rio Grande do Sul, cobrindo 63\% do seu território (IBGE, 2004). De tal maneira, a consolidação da pecuária data da ocupação dessa região, contribuindo com o desenvolvimento e dando abertura para a introdução de outras atividades produtivas, como o cultivo de trigo e arroz. Desse modo, há mais de 300 anos a pecuária vem fazendo parte não só da construção de uma região, mas também de sua história e das características de sua população (PESAVENTO, 1985).

Com isso, cabe salientar que a conjuntura atual das microrregiões Campanha Meridional e Serra do Sudeste vêm sendo dinamizada, apresentando uma diversidade de atividades produtivas concomitante à prevalência da pecuária. Diante desse contexto, verifica-se que a pecuária vem cada vez mais dividindo espaço com a silvicultura, lavouras de arroz, soja e trigo, fruticultura, dentre tantas outras atividades que denotam a diversidade econômica e social registrada nos municípios investigados, como será apresentado nas próximas seções.

\section{Dinâmica populacional, aspectos socioeconômicos e situação fundiária}

Os municípios de Bagé, Dom Pedrito, Piratini e Pinheiro Machado possuem uma área territorial, respectivamente, de 4.095,553 $\mathrm{km}^{2}, 5.192,120 \mathrm{~km}^{2}, 3.561,5 \mathrm{~km}^{2}$ e $2.227,9 \mathrm{~km}^{2}$ (FEE, 2011), estando localizados ao sul do Rio Grande do Sul (Figura 1).

\section{Figura 1 - Localização dos municípios de Bagé e Dom Pedrito (Campanha Maridional), Piratini e Pinheiro Machado (Serra do Sudeste).}

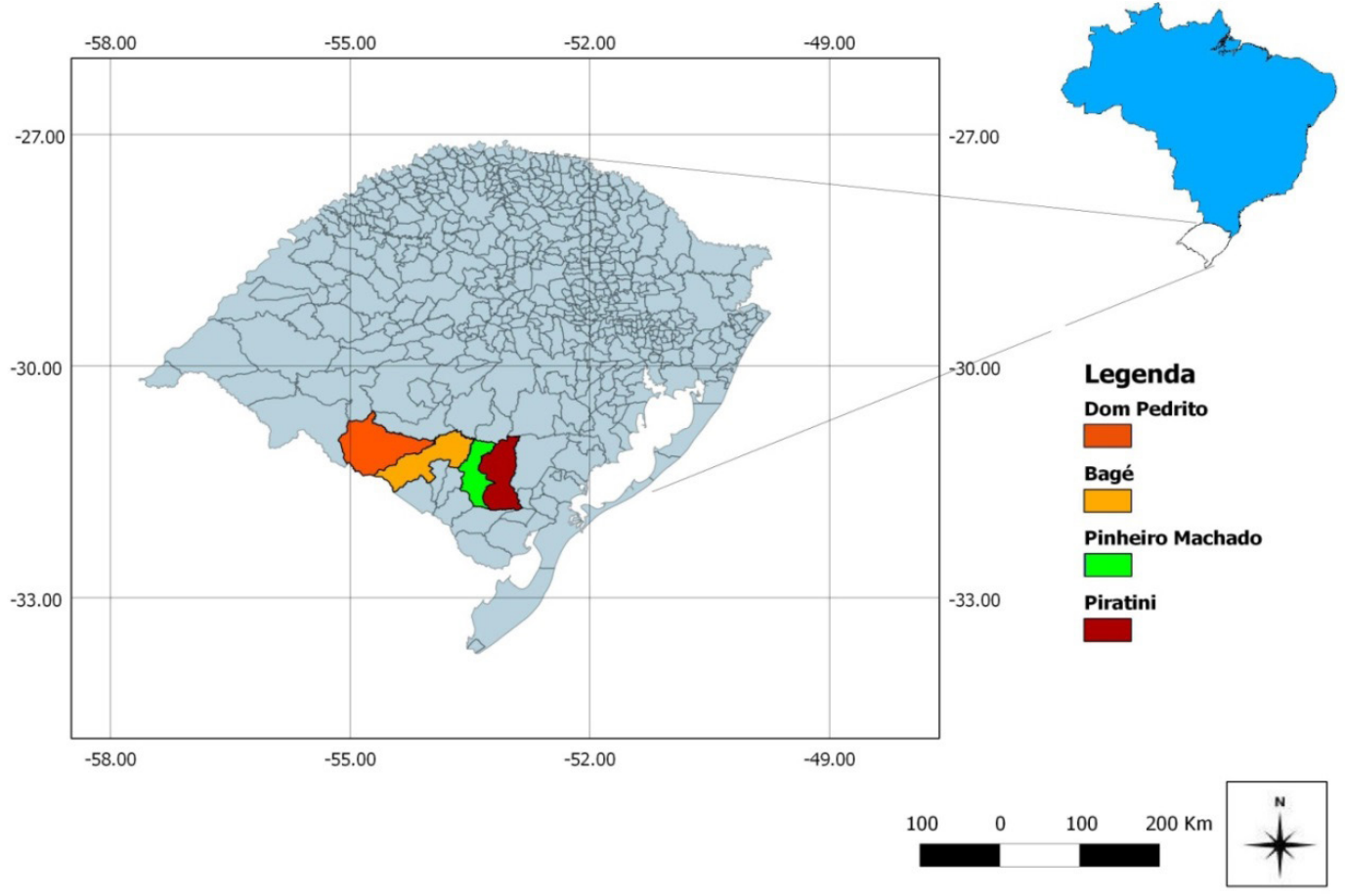


Segundo o Censo Populacional (IBGE, 2000a; 2010a) o número total de habitantes diminuiu nas últimas cinco décadas nos municípios de Bagé, Dom Pedrito e Pinheiro Machado, apenas em Piratini houve um pequeno aumento da população total, conforme pode ser visualizado na Tabela 1. Nos quatro municípios investigados, entre o período de 1970 a 2010, houve aumento da população urbana.

\section{Tabela 1 - Dinâmica populacional dos municípios Bagé, Dom Pedrito, Piratini e Pinheiro Machado no período de 1970 a 2010.}

\begin{tabular}{|c|c|c|c|c|c|c|c|c|c|c|}
\hline \multicolumn{11}{|c|}{ Ano do Censo Populacional } \\
\hline & \multicolumn{2}{|c|}{1970} & \multicolumn{2}{|c|}{1980} & \multicolumn{2}{|c|}{1991} & \multicolumn{2}{|c|}{2000} & \multicolumn{2}{|c|}{2010} \\
\hline & $\mathrm{N}^{\circ}$ & $\%$ & $\mathrm{~N}^{\circ}$ & $\%$ & $\mathrm{~N}^{\circ}$ & $\%$ & $\mathrm{~N}^{\circ}$ & $\%$ & $\mathrm{~N}^{\circ}$ & $\%$ \\
\hline \multicolumn{11}{|c|}{ Bagé } \\
\hline Rural & 30.549 & 34 & 30.282 & 30 & 26.643 & 22 & 21.477 & 18 & 19.029 & 16 \\
\hline Urbana & 59.731 & 66 & 69.851 & 70 & 92.324 & 78 & 97.290 & 82 & 97.765 & 84 \\
\hline Total & 90.280 & 100 & 100.133 & 100 & 118.967 & 100 & 118.767 & 100 & 116.794 & 100 \\
\hline \multicolumn{11}{|c|}{ Dom Pedrito } \\
\hline Rural & 12.216 & 37 & 9.101 & 26 & 5.763 & 15 & 4.615 & 11 & 3.643 & 9 \\
\hline Urbana & 20.585 & 63 & 26.049 & 74 & 32.291 & 85 & 35.795 & 89 & 35.255 & 91 \\
\hline Total & 32.801 & 100 & 35.150 & 100 & 38.054 & 100 & 40.410 & 100 & 38.898 & 100 \\
\hline \multicolumn{11}{|c|}{ Piratini } \\
\hline Rural & 21.542 & 88 & 14.554 & 72 & 10.631 & 60 & 9.561 & 49 & 8.271 & 42 \\
\hline Urbana & 2.902 & 12 & 5.570 & 28 & 7.024 & 40 & 9.853 & 51 & 11.570 & 68 \\
\hline Total & 24.444 & 100 & 20.124 & 100 & 17.655 & 100 & 19.414 & 100 & 19.841 & 100 \\
\hline \multicolumn{11}{|c|}{ Pinheiro Machado } \\
\hline Rural & 9.888 & 69 & 8.265 & 58 & 6.931 & 45 & 4.393 & 30 & 2.996 & 23 \\
\hline Urbana & 4.372 & 31 & 6.094 & 42 & 8.465 & 55 & 10.201 & 70 & 9.784 & 77 \\
\hline Total & 14.260 & 100 & 14.359 & 100 & 15.396 & 100 & 14.594 & 100 & 12.780 & 100 \\
\hline
\end{tabular}

Fonte: IBGE (Censo Populacional), 2000a; 2010a. Elaborado pelos autores.

Em contrapartida, o meio rural tem reduzido de modo crescente e significativo sua população, sobretudo nos municípios de Dom Pedrito e Pinheiro Machado, que atingiram a maior queda populacional no meio rural, ambos reduzindo 70\%. A redução verificada em Bagé e Piratini fica um pouco abaixo dos valores dos demais municípios, sendo $38 \%$ e $62 \%$, respectivamente. Cabe considerar que nos últimos anos houve em Bagé duas emancipações (Aceguá/1996 e Hulha Negra/1992), decorrendo em parte na redução populacional no rural desse município. De modo relevante, deve-se considerar o aumento da presença de assentamentos nos municípios investigados, os quais influenciam na dinâmica populacional e no número de estabelecimentos ativos nos municípios. No entanto, ainda não há dados que tratem de separar estas informações para, assim, realizar uma análise mais precisa.

Somado a essa redução populacional no meio rural, há que se considerar que a situação tornase complexa na medida em que atentamos para uma redução seletiva da população, distinguindose por sexo e por idade. De tal maneira, constata-se cada vez mais que as consequências desse processo de redução populacional no meio rural resultam no envelhecimento e na masculinização 
da população, haja vista a saída principalmente de jovens e indivíduos do sexo feminino (IBGE, 2010). Em estudo realizado por Matte, Spanevello e Andreatta (2015), no município de Dom Pedrito, as autoras constatam que têm havido um intenso processo de esvaziamento populacional do meio rural, especialmente acentuado entre jovens.

No que se refere aos dados socioeconômicos, o Índice de Desenvolvimento Humano ${ }^{3}$ (IDH) em nível municipal apontou que os municípios investigados possuem IDH classificado como alto desenvolvimento (PNUD, 2003). Em seus indicadores individuais, IDH Longevidade e IDH Educação, apresentam valores muito próximos entre si para os municípios. Cabe destacar que o IDH Educação é o componente com valor mais elevado para todos os municípios (Tabela 2).

\section{Tabela 2 - Índice de Desenvolvimento Humano (IDH, 2003) e Índice de Gini (2000) para os municípios de Bagé, Dom Pedrito, Piratini e Pinheiro Machado.}

\begin{tabular}{cccccc}
\hline Município & IDH & IDH Renda & IDH Longevidade & IDH Educação & Índice de Gini \\
\hline Bagé & 0,802 & 0,722 & 0,786 & 0,898 & 0,41 \\
Dom Pedrito & 0,783 & 0,712 & 0,761 & 0,875 & 0,42 \\
Piratini & 0,756 & 0,650 & 0,780 & 0,838 & 0,57 \\
Pinheiro Machado & 0,752 & 0,669 & 0,717 & 0,869 & 0,56 \\
\hline Fonte: PNUD - Programa das Nações Unidas para o Desenvolvimento, 2003. Elaborado pelos autores.
\end{tabular}

$\mathrm{O}$ índice de Gini ${ }^{4}$ que informa a distribuição de renda nos municípios de Bagé e Dom Pedrito ficou entre 0,41 a 0,42, sendo menor que o valor calculado para o estado do Rio Grande do Sul, que é de 0,55 (IBGE, 2000b). Segundo demonstrado pelo coeficiente, observa-se maior desigualdade de renda nos municípios de Piratini e Pinheiro Machado.

Ao que confere a situação fundiária conforme dados do IBGE (2006) apresentados na Tabela 3, os municípios de Piratini e Pinheiro Machado concentram o maior número de estabelecimentos no estrato de zero a 200 hectares, representando 88,9\% e 80,9\% do número total de estabelecimentos, respectivamente. Contudo, ao observar de modo mais detalhado, constata-se que os estabelecimentos de até 50 hectares representam mais da metade do número total de estabelecimentos com $65,9 \%$ e 55,5\%, ocupando apenas $14,2 \%$ e $9,1 \%$ da área total de Piratini e Pinheiro Machado, respectivamente. Em contrapartida, as propriedades acima de 500 hectares representam 4,4\% e $6 \%$ dos estabelecimentos, no entanto ocupam um montante $45 \%$ e $40 \%$ da área de cada município.

Em Bagé e Dom Pedrito, constata-se também uma proporção significativa de estabelecimentos com até 200 hectares, sendo $69,6 \%$ e 64,8\%, respectivamente. Verifica-se uma concentração de estabelecimento também no estrato de até 50 hectares, representado por $52 \%$ e $41,1 \%$ em apenas $3,1 \%$ e 2,3\% da área total do município. Por outro lado, o número de estabelecimentos acima de 500 hectares representa 15\% e 18\% do total de estabelecimentos, proporção bem superior a dos municípios de Piratini e Pinheiro Machado. A distribuição dos distintos estratos de estabelecimentos agropecuários pode estar diretamente relacionada às diversas

3 O Índice de Desenvolvimento Humano (IDH) é utilizado na classificação do grau de desenvolvimento. Sua elaboração tem na composição dados de expectativa de vida ao nascer, educação e PIB per capita (como um indicador do padrão de vida), variando de 0 a 1 . Quanto mais próximo de 1 o valor deste indicador, maior será o nível de desenvolvimento humano do país ou região (PNUD, 2000).

4 Coeficiente de Gini é comumente utilizado no cálculo da distribuição de renda, correspondendo a um número de 0 a 1 , sendo 0 (zero) completa igualdade de renda e 1 completa desigualdade. 
formas de relevo e cobertura vegetal presentes nos municípios, podendo permitir a compreensão das atuais atividades desenvolvidas nesses municípios, aspecto que será abordado na próxima seção.

Tabela 3 - Estrutura fundiária dos municípios de Bagé, Dom Pedrito, Piratini e Pinheiro Machado no ano de 2006.

\begin{tabular}{|c|c|c|c|c|c|c|c|c|}
\hline \multirow{2}{*}{$\begin{array}{l}\text { Tamanho de } \\
\text { Propriedade } \\
\text { (ha) }\end{array}$} & \multirow{2}{*}{$\begin{array}{c}\text { Bagé } \\
\% \\
\text { estabelecimentos }\end{array}$} & \multicolumn{3}{|c|}{ Dom Pedrito } & \multicolumn{2}{|l|}{ Piratini } & \multicolumn{2}{|c|}{ Pinheiro Machado } \\
\hline & & $\begin{array}{c}\% \\
\text { área }\end{array}$ & $\begin{array}{c}\% \\
\text { estabelecimentos }\end{array}$ & $\begin{array}{c}\% \\
\text { área }\end{array}$ & $\begin{array}{c}\% \\
\text { estabelecimentos }\end{array}$ & $\begin{array}{c}\% \\
\text { área }\end{array}$ & $\begin{array}{c}\% \\
\text { estabelecimentos }\end{array}$ & $\begin{array}{c}\% \\
\text { área }\end{array}$ \\
\hline$<10$ & 23,6 & 0,3 & 16,5 & 0,2 & 13,9 & 0,7 & 12,7 & 0,5 \\
\hline $10 \mathrm{a}<50$ & 28,4 & 2,8 & 24,6 & 2,1 & 52 & 13,5 & 42,8 & 8,6 \\
\hline $50 \mathrm{a}<100$ & 9,7 & 2,7 & 12,6 & 3,1 & 14,2 & 10,1 & 14,9 & 8,2 \\
\hline $100 \mathrm{a}<200$ & 7,9 & 4,4 & 11,1 & 5,2 & 8,8 & 12,3 & 10,5 & 11,4 \\
\hline $200 \mathrm{a}<500$ & 12,2 & 15,5 & 14,7 & 16,3 & 6,1 & 18,9 & 10,7 & 25,5 \\
\hline $500 \mathrm{a}<1000$ & 8,2 & 22,5 & 10 & 23,5 & 3 & 20,4 & 4,5 & 23,7 \\
\hline $1000 \mathrm{a}<2500$ & 6,0 & 35,4 & 7 & 36,1 & 1,1 & 14,1 & 1,5 & 16 \\
\hline 2500 ha e mais & 1,2 & 16,5 & 1,2 & 13,5 & 0,3 & 10 & 0,1 & 0 \\
\hline $\begin{array}{l}\text { Produtor sem } \\
\text { área }\end{array}$ & 2,8 & 0 & 2,3 & 0 & 0,6 & 0 & 2,3 & 0 \\
\hline
\end{tabular}

Fonte: IBGE (2006). Elaborado pelos autores.

No que diz respeito a alguns aspectos econômicos os quatro municípios investigados têm sua economia diretamente relaciona à atividade pecuária, desenvolvida sobre campos cobertos pelo Bioma Pampa. Recentemente outras atividades vêm diversificando e estimulando a economia municipal e a composição do PIB. Ao observar a Tabela 4, verifica-se que o município de Dom Pedrito apresenta um PIB per capita significativamente alto se comparado aos demais municípios chegando a $\mathrm{R} \$ 15.468,00$.

Tabela 4 - Evolução da renda per capita (2008) e do valor agregado para os municípios de Bagé, Dom Pedrito, Piratini e Pinheiro Machado nos anos de 2000 e 2009.

\begin{tabular}{cccccc}
\hline \multirow{2}{*}{ Município } & \multirow{2}{*}{ Ano } & PIB per capita & \multicolumn{3}{c}{ Estrutura do VAB (R\$ mil) } \\
\cline { 4 - 6 } & & & Agropecuária & Indústria & Serviços \\
\hline \multirow{2}{*}{ Bagé } & 2000 & 4.888 & 48.546 & 84.691 & 400.141 \\
& 2009 & 10.015 & 107.297 & 154.968 & 822.504 \\
\hline \multirow{2}{*}{ Dom } & 2000 & 5.570 & 62.930 & 38.904 & 112.853 \\
Pedrito & 2009 & 15.468 & 242.975 & 108.341 & 277.358 \\
\hline \multirow{2}{*}{ Piratini } & 2000 & 3.627 & 26.083 & 5.513 & 36.984 \\
& 2009 & 8.671 & 65.161 & 15.823 & 102.903 \\
\hline Pinheiro & 2000 & 4.955 & 13.521 & 20.684 & 32.415 \\
Machado & 2009 & 11.326 & 39.546 & 35.173 & 74.647 \\
\hline \hline
\end{tabular}

Fonte: FEE, 2008b. (VER PIB, 2008 e VAB 2000 e 2009). Elaborado pelos autores.

Esse município também apresenta maior participação de Valor Agregado Bruto (VAB) agropecuário. Contudo, essa categoria de análise não separa a atividade pecuária das atividades agrícolas, o que pode explicar valor significativamente alto, além da extensão territorial do município em relação aos demais. 
Quanto à dinâmica de crescimento no setor agropecuário, todos os municípios obtiveram crescimento entre 2000 a 2009. Apesar do crescimento do VAB agropecuário observado as atividades relacionadas vêm deparando-se com adversidades climáticas frequentes, principalmente por conta de períodos de estiagem, causando retração do PIB. Segundo dados da FEE (2012), o setor de maior impacto sobre o desempenho geral da economia no estado foi o PIB agropecuário, refletindo em uma redução no segundo trimestre de 2012, em comparação com o mesmo período de 2011, de 46,4\% do PIB agropecuário.

\section{Dinâmicas produtivas em metamorfose no "Pampa"}

Essa seção inicia destacando, primeiramente, as transformações que tem ocorrido sobre a estrutura do Bioma Pampa,já que é sobre esse ecossistema que teve origem a atividades produtivas hoje em desenvolvimento nas microrregiões analisadas. Um mapeamento da cobertura vegetal natural remanescente para toda a abrangência do Bioma Pampa foi realizado pela Universidade Federal do Rio Grande do Sul (UFRGS) e EMBRAPA Clima Temperado e EMBRAPA Pecuária Sul. O resultado desse mapeamento revelou o predomínio de uma estrutura vegetal em transição nos municípios de Pinheiro Machado e Piratini, entretanto com uma baixa ocupação de áreas campestres (Tabela 5).

Tabela 5 - Proporção da cobertura vegetal para o ano de 2007.

\begin{tabular}{|c|c|c|c|c|c|c|c|c|c|}
\hline \multirow[b]{2}{*}{ Município } & \multirow[b]{2}{*}{ Área $\left(\mathrm{km}^{2}\right)$} & \multicolumn{6}{|c|}{ Tipo de cobertura vegetal $\left(\mathrm{km}^{2}\right)$} & \multirow[b]{2}{*}{$\begin{array}{c}\text { Total } \\
\left(\mathrm{km}^{2}\right)^{*}\end{array}$} & \multirow{2}{*}{$\begin{array}{c}\text { Áreas não } \\
\text { remanescentes } \\
(\%)\end{array}$} \\
\hline & & $\begin{array}{c}\text { Campestre } \\
\text { (ha) }\end{array}$ & $\%$ & $\begin{array}{c}\text { Florestal } \\
\text { (ha) }\end{array}$ & $\%$ & $\begin{array}{c}\text { Transição } \\
\text { (ha) }\end{array}$ & $\%$ & & \\
\hline Bagé & 4078,2 & $\begin{array}{l}555,4 \\
\end{array}$ & 14 & 229,5 & $\overline{5,6}$ & 1942,2 & 477,6 & 2727,1 & 33,1 \\
\hline Dom Pedrito & 5167,8 & 996,3 & 19 & 118,8 & 2,3 & 1497,8 & 28,9 & 2612,9 & 49,4 \\
\hline Piratini & 3554,3 & 167,9 & 4,7 & 312,6 & 8,8 & 1939,8 & 54,6 & 2420,3 & 31,9 \\
\hline $\begin{array}{l}\text { Pinheiro Ma- } \\
\text { chado }\end{array}$ & 2223,6 & 179,5 & 8,1 & 78,9 & 3,5 & 1730,3 & 77,8 & 1988,8 & 10,6 \\
\hline
\end{tabular}

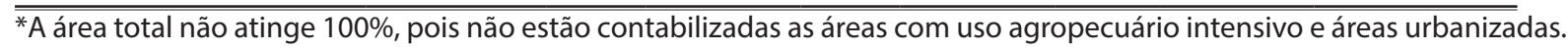
Fonte: PROBIO - Cobertura vegetal do Bioma Pampa (2007).

Assim, as áreas em transição podem ser compreendidas pela presença de um tipo de remanescente representado por um mosaico de campo e mata nativa, com formação herbáceaarbustiva nativa, sob o uso pecuário e de floresta nativa. Sua ocorrência é predominante sobre solos rasos com afloramento rochoso, em relevo de variação frequente entre colinas e vales, característico da região do Serra do Sudeste ou Escudo Sul-Riograndense (PROBIO, 2007). Como destacados por Matei e Filippi (2013), as áreas compreendidas pelo Bioma Pampa passaram a sofrer mudanças desde a época da colonização, especialmente com as demarcações de fronteiras, com a introdução da pecuária e o estabelecimento da estrutura fundiária de médias e grandes propriedades.

É possível observar nos municípios de Bagé e Dom Pedrito maior proporção de áreas denominadas de campestres. Essas áreas são caracterizadas por sua formação herbácea nativa, com boa cobertura de solo, podendo haver faixas arenosas e ausência de cultivos ou evidência de uso agrícola passado (PROBIO, 2007). Esses municípios tem sido palco de certa expansão de 
cultivos agrícolas, tendo seu avanço facilitado pela presença de áreas formadas por relevos planos, pouco ondulados e pouco pedregosos.

Dado que as denominações campestre, florestal e transição foram consideradas como áreas remanescentes, considera-se áreas não remanescentes aquelas utilizadas, em passado recente, com atividade agrícola e áreas degradadas pelo excesso de pastoreio. Com efeito, estas áreas representam 33,1\% em Bagé, 49,4\% Dom Pedrito, 31,9\% Piratini e 10,6\% em Pinheiro Machado. A tabela acima ilustra a condição atual da cobertura vegetal do Bioma Pampa.

A comprovação das transformações em andamento nas microrregiões estudadas é evidenciada em dados divulgados pelo Programa das Nações Unidas para o Desenvolvimento PNUD, indicando a classificação dos vinte municípios que mais suprimiram sua vegetação natural dando espaço para outras atividades e formas de uso do solo. Dentre eles estão Dom Pedrito com 51,5\% da área suprimida, Bagé com 37,6\% e Piratini com36,7\%. Apesar de Pinheiro Machado ficar fora dessa lista ele não está isento da supressão de área, sua participação na reconversão produtiva atinge 14,9\% de seu território. Segundo dados do Ministério do Meio Ambiente (MMA, 2010), atualmente a supressão da vegetação nativa do Bioma Pampa já atinge 54\% da área original de $177.767 \mathrm{~km}^{2}$. Entre o período de 2002 e 2008 o Bioma Pampa contabilizou uma perda de 251.400 hectares de vegetação nativa, sendo o segundo bioma mais devastado do país (MMA, 2010).

Assim, o avanço da produção agrícola e da silvicultura, a implantação de pastagens cultivadas, o sobrepastejo e a erosão, tem denotado uma nova paisagem ao Bioma Pampa (OVERBECK et al., 2009; SUERTEGARAY, PIRES DA SILVA, 2009). Segundo Behling et al. (2009, p. 15), a vegetação original está sendo modificada pelo avanços dessas atividades:

[...] os atuais ecossistemas, tanto florestais como campestres, são fortemente influenciados pelas atividades humanas. A remoção da floresta e a alteração da paisagem [campo nativo], por meio da agricultura, pastoreio e plantios de Pinus e Eucalyptus, têm mudado claramente a vegetação original.

As principais atividades que vêm ganhando espaço produtivo e econômico nas microrregiões estudadas é o cultivo de grãos (soja, trigo) e a silvicultura. A lavoura temporária de arroz é a que mais cresceu nos últimos anos, sendo acompanhada pela soja e a lavoura de milho. Segundo Overbeck et al. (2009) a expansão das atividades agrícolas ocorre de modo mais constante nas últimas três décadas, no entanto, sua ocorrência data de 1940, principalmente dos cultivos de milho, soja, trigo e arroz. Segundo Verdum (2004, p. 53), há um deslocamento de "novos exploradores" vindos do norte do estado, considerados pelo autor como principais responsáveis pela implantação de cultivos mecanizados de lavouras de grãos. Esses indivíduos, por meio da compra ou arrendamento da terra, dão início a uma pressão sobre solos frágeis e sobre a vegetação herbácea dos municípios. Conforme a Tabela 6, no município de Dom Pedrito o cultivo de lavoura temporária ocupa 157.188 hectares da área total do município, representando 38\% do seu território.

O município de Pinheiro Machado apresenta menor presença dessa atividade em seu território, sendo que essas lavouras representam apenas $5 \%$ da área total do município. De acordo com Bertê (2004), o manejo realizado no solo, para o cultivo dessas lavouras, têm alterado suas 
características físicas e químicas em proporções ainda não diagnosticadas, mas provocando perdas na qualidade e conformação do solo gerada pela sua degradação.

Tabela 6 - Formas de utilização da terra nos municípios de Bagé, Dom Pedrito, Piratini e Pinheiro Machado no ano de 2006.

\begin{tabular}{|c|c|c|c|c|}
\hline \multirow{3}{*}{ Grupo de atividade econômica } & \multicolumn{2}{|c|}{ Bagé } & \multicolumn{2}{|c|}{ Dom Pedrito } \\
\hline & \multicolumn{4}{|c|}{ Área dos estabelecimentos agropecuários } \\
\hline & ha & $\%$ & ha & $\%$ \\
\hline Lavoura temporária & 43.822 & 15 & 157.188 & 38 \\
\hline Horticultura e floricultura & 1.981 & 0,7 & 2.504 & 0,6 \\
\hline Lavoura permanente & 1.853 & 0,6 & 2.038 & 0,5 \\
\hline $\begin{array}{l}\text { Sementes, mudas e outras formas de } \\
\text { propagação vegetal }\end{array}$ & - & - & - & - \\
\hline Pecuária e criação de outros animais & 248.156 & 83 & 248.582 & 60 \\
\hline $\begin{array}{l}\text { Produção florestal - florestas } \\
\text { plantadas }\end{array}$ & 3.953 & 1,3 & 2.866 & 0,7 \\
\hline Produção florestal - florestas nativas & 8 & 0,002 & - & - \\
\hline Pesca & - & - & - & - \\
\hline Aquicultura & - & - & - & - \\
\hline TOTAL & 299.771 & 100 & 413.782 & 100 \\
\hline \multirow{3}{*}{ Grupo de atividade econômica } & & & & chado \\
\hline & \multicolumn{4}{|c|}{ Área dos estabelecimentos agropecuários } \\
\hline & ha & $\%$ & ha & $\%$ \\
\hline Lavoura temporária & 52.298 & 18 & 11.004 & 5 \\
\hline Horticultura e floricultura & 2.024 & 0,7 & 3.892 & 2 \\
\hline Lavoura permanente & 4.843 & 2 & 460 & 0,2 \\
\hline $\begin{array}{l}\text { Sementes, mudas e outras formas de propagação } \\
\text { vegetal }\end{array}$ & - & - & 225 & 0,1 \\
\hline Pecuária e criação de outros animais & 166.840 & 59 & 160.542 & 78 \\
\hline Produção florestal - florestas plantadas & 58.733 & 21 & 38.083 & 17 \\
\hline Produção florestal - florestas nativas & - & - & - & - \\
\hline Pesca & - & - & - & - \\
\hline Aquicultura & 313 & 0,1 & 53 & 0,02 \\
\hline TOTAL & 285.146 & 100 & 214.506 & 100 \\
\hline
\end{tabular}

Fonte: IBGE, 2006. Elaborado pelos autores.

Além das lavouras também é possível observar um avanço de florestas plantadas, principalmente nos municípios da microrregião da Serra do Sudeste. Segundo Overbeck et al. (2009), o plantio de árvores exóticas têm sido direcionadas a produção de celulose. Corroborando com esta afirmação, a Associação Gaúcha de Empresas Florestais (AGEFLOR) apresenta a dimensão da inserção das três principais espécies cultivadas na produção de celulose nos últimos anos. Segundo Bertê (2004), a expansão de monoculturas florestais no estado tem impulso em 1956, por conta da consolidação de uma lei de incentivo fiscais, que estimulam significativamente o florestamento do território, favorecendo a indústria de celulose e papel. 
Os riscos dessa reconversão produtiva e, principalmente, da intensificação produtiva em espaços agrícolas, resultarão em consequências significativas para o ambiente, como a degradação dos solos e dos recursos hídricos, desmatamento, mudanças climáticas regionais, perda de biodiversidade, entre outros fatores (Porto; Soares, 2012; Davidson et al., 2012; Wesz Jr., 2016). Enquanto no sul do país os pecuaristas estão perdendo suas áreas de pastagem natural, dando espaço para a entrada do cultivo de lavoura de grãos e da silvicultura, paradoxalmente, no norte do país, principalmente na Amazônia, derrubam-se áreas com florestas nativas para entrada da pecuária, transformando parcelas florestais naturais em grandes extensões de pastagens cultivadas (MORALES GROSSKOPF, 2011; FEARNSIDE, 2005; PIKETTY et al., 2005; SOARESFILHO et al., 2006). O que há em comum em ambas as situações é a supressão dos recursos naturais, movidos por um conjunto particular de interesses de um projeto desenvolvimentista, gerando uma importante e cada vez maior perda da identidade cultural e da continuação dos sistemas produtivos originais desses contextos. As consequências da conversão dessas áreas podem estar refletindo em alterações no ambiente, como períodos cada vez mais rigorosos e extensos de seca (SOARES-FILHO et al., 2006; DAVIDSON et al., 2012). Como demonstrado na tabela abaixo, a expansão dessa atividade é evidente, ocupando atualmente mais de quinhentos mil hectares, tendo um crescimento de 36\% em cinco anos (2002 a 2007).

\section{Tabela 7 - Área plantada (ha) com silvicultura no Rio Grande do Sul entre 2002 e 2007.}

\begin{tabular}{cccc}
\hline Espécie plantada & $\mathbf{2 0 0 2}$ & $\mathbf{2 0 0 7}$ & Crescimento \\
& UFSM & AGEFLOR & \% \\
\hline Pinus & 150.000 & 182.378 & 17 \\
Eucalipto & 110.000 & 222.245 & 51 \\
Acácia & 100.000 & 158.961 & 37 \\
Total & $\mathbf{3 6 0 . 0 0 0}$ & $\mathbf{5 6 3 . 5 8 4}$ & $\mathbf{3 6}$ \\
\hline
\end{tabular}

Fonte: AGEFLOR, 2009.

As constatações apontadas acima evidenciam uma atividade pecuária que vem cedendo (ou perdendo) espaço para uma diversidade de outras atividades (agricultura, silvicultura, fruticultura). No entanto, apesar da expansão das atividades agrícolas e da silvicultura mencionadas anteriormente, a pecuária permanece sendo a principal atividade desenvolvida nos municípios estudados. Corroborando com essa afirmação, Girardi (2008) aponta que a região sul tem atualmente como principais atividades a pecuária, a rizicultura e as lavouras de soja. Ao observar de modo mais detalhado a Tabela 8 observa-se que a atividade pecuária e a criação de outros animais se destaca dentre as demais atividades, ocupando mais da metade da área total dos municípios investigados, sendo 83\% em Bagé, 60\% em Dom Pedrito, 59\% em Piratini e 78\% em Pinheiro Machado. Apesar de a pecuária representar a atividade produtiva predominante nos municípios de Dom Pedrito e Piratini, sua ocupação é inferior à dos demais municípios, podem estar diretamente relacionados ao avanço das demais atividades já mencionadas. 
No que diz respeito especificamente à criação de animais, a Tabela 9 apresenta o número de estabelecimentos agropecuários e o respectivo número de estabelecimentos que desenvolvem a atividade pecuária e a criação de outros animais, distribuídos em distintos estratos de tamanho de área. Observa-se que em grande medida a maior parte dos estabelecimentos agropecuários dos municípios investigados desenvolve atividade pecuária ou criação de outros animais. Sendo apenas uma parcela reduzida de estabelecimentos agropecuários que não desenvolvem a atividade pecuária nem criam outros tipos de animais, correspondendo a 8\% em Bagé, 27\% em Dom Pedrito, $38 \%$ em Piratini e 21\% Pinheiro Machado.

Tabela 8 - Número de estabelecimentos com atividade pecuária e criação de outros animais nos municípios de Bagé, Dom Pedrito, Piratini e Pinheiro Machado (2006).

\begin{tabular}{|c|c|c|c|c|c|c|}
\hline & \multicolumn{3}{|c|}{ Bagé } & \multicolumn{3}{|c|}{ Dom Pedrito } \\
\hline Tamanhos (ha) & Total & Com animais & $\%$ & Total & Com animais & $\%$ \\
\hline$<10$ & 259 & 259 & 100 & 232 & 181 & 78 \\
\hline $10 a<50$ & 340 & 340 & 100 & 347 & 285 & 82 \\
\hline $50 \mathrm{a}<100$ & 116 & 100 & 82 & 178 & 137 & 77 \\
\hline $100 a<200$ & 95 & 79 & 83 & 157 & 104 & 66 \\
\hline $200 a<500$ & 146 & 119 & 82 & 207 & 141 & 68 \\
\hline $500 \mathrm{a}<1000$ & 98 & 84 & 86 & 141 & 88 & 62 \\
\hline $1000 a<2500$ & 72 & 61 & 85 & 98 & 55 & 56 \\
\hline 2500 ha e mais & 14 & 10 & 71 & 17 & 7 & 41 \\
\hline Produtor sem área & 34 & 32 & 94 & 32 & 30 & 94 \\
\hline \multirow[t]{2}{*}{ TOTAL } & 1174 & 1084 & 92 & 1409 & 1028 & 73 \\
\hline & \multicolumn{3}{|c|}{ Piratini } & \multicolumn{3}{|c|}{ Pinheiro Machado } \\
\hline Tamanhos (ha) & Total & Com animais & $\%$ & Total & $\begin{array}{c}\text { Com } \\
\text { animais }\end{array}$ & $\%$ \\
\hline$<10$ & 404 & 244 & 60 & 209 & 157 & 75 \\
\hline $10 a<50$ & 1514 & 1062 & 70 & 703 & 531 & 76 \\
\hline $50 \mathrm{a}<100$ & 414 & 305 & 74 & 245 & 209 & 85 \\
\hline $100 \mathrm{a}<200$ & 255 & 168 & 66 & 172 & 144 & 82 \\
\hline $200 a<500$ & 178 & 113 & 44 & 175 & 144 & 82 \\
\hline $500 a<1000$ & 86 & 45 & 52 & 73 & 55 & 75 \\
\hline $1000 a<2500$ & 32 & 17 & 53 & 25 & 18 & 72 \\
\hline 2500 ha e mais & 9 & 3 & 33 & 2 & 1 & 50 \\
\hline Produtor sem área & 18 & 11 & 61 & 38 & 34 & 89 \\
\hline TOTAL & 2.910 & 1.968 & 68 & 1.642 & 1.293 & 79 \\
\hline
\end{tabular}

Fonte: IBGE, 2006.

Conforme os dados da tabela anterior, Bagé é o município com maior número de estabelecimentos que desenvolvem a atividade pecuária, com uma média de $92 \%$ dos estabelecimentos. Na sequência está Pinheiro Machado com 79\%, Dom Pedrito com 73\% e Piratini com 68\%. Observa-se que os estabelecimentos nos estratos de 50 a 200 hectares dos municípios de Bagé e Pinheiro Machado possuem atividade pecuária em mais de $80 \%$ do total de 
estabelecimentos. Diferente de Dom Pedrito e Piratini, que possuem uma proporção um pouco menor de estabelecimentos que realizam a atividade pecuária e a criação de pequenos animais. Quando observado o número de animais entre o período de 2000 a 2010, visualizamos uma redução no montante de alguns rebanhos, como pode ser observado na Tabela 9.

\section{Tabela 9 - Número de animais nos municípios de Bagé, Dom Pedrito, Piratini e Pinheiro Machado nos anos de 2000 e 2010.}

\begin{tabular}{cccccccc}
\hline \multirow{2}{*}{ Descrição } & \multicolumn{3}{c}{ Bagé } & \multicolumn{3}{c}{ Dom Pedrito } \\
& $\mathbf{2 0 0 0}$ & $\mathbf{2 0 1 0}$ & $\mathbf{\%}$ & $\mathbf{2 0 0 0}$ & $\mathbf{2 0 1 0}$ & $\mathbf{\%}$ \\
\hline Bovinos & 400.467 & 332.615 & $-17 \%$ & 406.067 & 423.684 & $4 \%$ \\
Equinos & 19.849 & 14.059 & $-29 \%$ & 16.107 & 18.430 & $14 \%$ \\
Bubalinos & 1.351 & 1.305 & $-3 \%$ & 4.426 & 979 & $-78 \%$ \\
Caprinos & 4.112 & 3.055 & $-26 \%$ & 294 & 253 & $-14 \%$ \\
Ovinos & 220.153 & 113.701 & $-48 \%$ & 181.690 & 147.859 & $-19 \%$ \\
& \multicolumn{7}{c}{ Pinheiro Machado } \\
\hline Descrição & $\mathbf{2 0 0 0}$ & $\mathbf{2 0 1 0}$ & $\mathbf{9}$ & $\mathbf{2 0 0 0}$ & $\mathbf{2 0 1 0}$ & $\mathbf{\%}$ \\
\hline Bovinos & 160.415 & 174.884 & $9 \%$ & 163.091 & 163.137 & $0,03 \%$ \\
Equinos & 6.055 & 6.760 & $12 \%$ & 7.663 & 4.302 & $-44 \%$ \\
Bubalinos & 578 & 90 & $-84 \%$ & 706 & 1.749 & $59 \%$ \\
Caprinos & 1.317 & 1.890 & $44 \%$ & 1.548 & 1.095 & $-29 \%$ \\
Ovinos & 119.612 & 94.131 & $-21 \%$ & 129.407 & 148.292 & $14 \%$ \\
\hline
\end{tabular}

Fonte: IBGE, 2010. Elaborado pelos autores.

Observa-se que apesar de Bagé ainda possuir o maior número de estabelecimentos com atividade pecuária houve uma queda no número de bovinos e ovinos no município, sendo de $17 \%$ e 48\%, respectivamente. Apesar dos demais municípios apresentarem crescimento no número de bovinos, essa proporção é relativamente baixa para o período de tempo analisado (dez anos). Ainda assim, visualiza-se uma significativa queda no número de ovinos nos municípios de Dom Pedrito (19\%) e Piratini (21\%).

\section{Considerações finais}

Nos aspectos produtivos, se observa que a pecuária de corte tem cedido espaço para outras atividades produtivas, particularmente para as lavouras agrícolas e de silvicultura, presentes nas estatísticas analisadas. Os impactos sociais da presença dessas atividades merecem ser investigados e, em longo prazo, novos estudos devem ser realizados para verificar quais aspectos têm sido modificadas juntamente com essas novas atividades. Contudo, diante deste cenário, alguns dos impactos decorrentes dessas transformações no sul do Rio Grande do Sul, em especial nas microrregiões estudadas, apontam para consequências como a elevação do preço da terra, redução de áreas destinadas à pecuária sobre campos naturais, pressão à modernização da atividade, supressão do Bioma Pampa e perda da biodiversidade, consequências essas potencialmente capazes de gerar diferentes situações de vulnerabilidade à atividade pecuária.

É evidente que a pecuária de corte, em todas as suas formas sociais e produtivas, se encontra em exposição a diversas situações de vulnerabilidade. Desse modo, em anos recentes, 
as microrregiões investigadas vêm passando por mudanças no contexto das estratégias de desenvolvimento, o que tem acarretado em transformações de ordem social, econômica e ambiental. As implicações dessas mudanças sobre o futuro da pecuária ainda são incertos, assim como a inserção dessas novas atividades produtivas. Pouco se sabe sobre os mercados que estão sendo construídos e quem são os principais atores e protagonistas desse novo cenário que é possível visualizar na região sul do estado. A atividade pecuária, que representa a principal atividade produtiva da região tem sido influenciada pelas mudanças ocorridas nas microrregiões. Diante desse contexto, é possível questionar qual o futuro ou mesmo que pecuária irá permanecer diante desse novo contexto.

Nota-se a expansão de "novas" atividades tem influenciado indiretamente a realização da atividade pecuária, passando a disputar áreas de terra e substituindo as pastagens nativas por lavouras, além disso, tem afetado a flora e fauna do Bioma Pampa frente ao uso de defensivos agrícolas, assim como a saúde da população rural que convive com a atividade e têm ficado exposta as consequências dessa atividade. Por se tratar de uma atividade em que a expansão em larga escala é recente, merece, portanto, atenção para estudos acadêmicos que possam avaliar o impacto social e ambiental dessas atividades, e o que isso implica em projetos e propostas de desenvolvimento rural construídos na e para a região.

\section{Referências}

ASSOCIAÇÃO GAÚCHA DE EMPRESAS FLORESTAIS - AGEFLOR. Setor de celulose e papel. 2009. Disponível em: <http://www.ageflor.com.br/upload/biblioteca/ Setor_de_celulose_e_papel_Mar\%E7o_2009.pdf >. Acesso em 20 mar. 2014.

BEHLING, Hermann et al. Dinâmica dos campos no sul do Brasil durante o Quaternário Tardio. In: PILLAR, Valério De Patta; MÜLLER, Sandra Cristina; CASTILHOS, Zélia Maria de Souza; JACQUES, Aino Victor Ávila. (Org.). Campos Sulinos - conservação e uso sustentável da biodiversidade. Brasília: Ministério do Meio Ambiente, 2009.p. 13-25.

BERTÊ, Ana Maria de Aveline. Problemas ambientais no Rio Grande so Sul: uma tentativa de aproximação. In: VERDUM, Roberto; BASSO, Luís A.; SUERTEGARAY, Dirce M. A. (Org.). Rio Grande do Sul: paisagens e territórios em transformação. Porto Alegre: Editora da UFRGS, 2004. p. 71-83.

BILENCA, David; MIÑARRO, Fernando. Identificación de Áreas Valiosas de Pastizales (AVPs) en las Pampas y Campos de Argentina, Uruguay y sur de Brasil. Buenos Aires: Fundación Vida Silvestre Argentina, 2004.

FUNDAÇÃO DE ECONOMIA E ESTATÍSTICA. Índice de Desenvolvimento Socioeconômico (IDESE). 2008a. Disponível em: <http://www.fee.tche.br/sitefee/pt/ estatisticas_idese_php>.Acesso em: 10 out. 2011.

FUNDAÇÃO DE ECONOMIA E ESTATÍSTICA. PIB e PIB per capita a preço de mercado - 2008. 2008b. Disponível em: <http://www.fee.tche.br/sitefee/pt/content/ estatisticas/pg_pib_municipal_sh_pib_nova.php?ano=2008\&serie=1999-2008\&letra=G>. 
Acesso em: 6 de ago. 2010.

FUNDAÇÃO DE ECONOMIA E ESTATÍSTICA. Resumo estatístico RS. 2011. Disponível em: <http://www.fee.tche.br/sitefee/pt/content/resumo/index.php>. Acesso em 26 set. 2011.

GIRARDI, Eduardo Paulo. Atlas da Questão Agrária Brasileira. 2008. Disponível em: <http://www2.fct.unesp.br/nera/atlas/>. Acesso em: 14 set. 2011.

INSTITUTO BRASILEIRO DE GEOGRAFIA E ESTATÍSTICA. Censo Agropecuário 2006. Rio de Janeiro: IBGE, 2009.

INSTITUTO BRASILEIRO DE GEOGRAFIA E ESTATÍSTICA. Censo da População, 2000. Brasília, 2000a. Disponível em: <http://www.sidra.ibge.gov.br/bda/ tabela/listabl.asp?z=t\&c=200>. Acesso em: 10 out. 2011.

INSTITUTO BRASILEIRO DE GEOGRAFIA E ESTATÍSTICA. Censo demográfico, 2010a. Disponível em: <http://www.sidra.ibge.gov.br/bda/tabela/listabl. asp? $c=1552 \& z=c d \& o=5>$. Acesso em 15 nov. 2011.

INSTITUTO BRASILEIRO DE GEOGRAFIA E ESTATÍSTICA. Cidades, 2000. Brasília, 2000b. Disponível em: <http://www.ibge.gov.br/cidadesat/topwindow.htm?1>. Acesso em: 10 mai. 2011.

INSTITUTO BRASILEIRO DE GEOGRAFIA E ESTATÍSTICA. Mapa da vegetação do Brasil e Mapa de Biomas do Brasil. 2004. Disponível em: <http://www. ibge.gov.br/home/presidencia/noticias/noticia_visualiza.php?id_noticia=169>. Acesso em: 06 de jun. 2011.

INSTITUTO BRASILEIRO DE GEOGRAFIA E ESTATÍSTICA. Pecuária 2006. Rio de Janeiro: IBGE, 2006. Disponível em: <http://www.sidra.ibge.gov.br/bda/tabela/ listabl.asp? $\mathrm{z}=\mathrm{t} \& \mathrm{o}=24 \& \mathrm{i}=\mathrm{P} \& \mathrm{c}=1244>$. Acesso em: 23 nov. 2011.

INSTITUTO BRASILEIRO DE GEOGRAFIA E ESTATÍSTICA. Produção da Pecuária Municipal, 2010b. Rio de Janeiro: IBGE, 2011.

MAESTRI, Mário. O Escravo do Rio Grande do Sul: trabalho, resistência e sociedade. 3. ed., Porto Alegre: Editora da UFRGS, 2006. 199 p.

MATEI, Ana Paula; FILIPPI, Eduardo E. O Bioma Pampa e o desenvolvimento socioeconômico em Santa Vitória do Palmar. Ensaios FEE, Porto Alegre, v.34, Número Especial, p. 739-764, 2013.

MATTE, Alessandra; SPANEVELLO, Rosani Marisa; ANDREATTA, Tanice. Perspectivas de sucessão em propriedades de pecuária familiar no município de Dom Pedrito - RS. HOLOS, [S.1.], Rio Grande do Norte, v. 1, p. 144-159, fev. 2015. 
MINISTÉRIO DO MEIO AMBIENTE. Bioma Pampa.2010. Disponível em: <http:// www.mma.gov.br/biomas/pampa>. Acesso em: 18 ago. 2012.

MIRANDA, A. C. Análise dos dados de estabelecimentos rurais na microrregião de Santiago, RS. Porto Alegre: EMATER RS/ASCAR, 2000. 8 p.

MORAES, Carlos Dante de. Figuras e ciclos da história rio-grandense. Rio de Janeiro: Globo, 1959. 229 p.

MORALES GROSSKOPF, Hermes et al. South American Livestock Farming Expansion: the long way to sustainability. In: KAMMILI, Trish; HUBERT, Bernard; TOURRAND, Jean-François. (Eds.). A paradigm shift in livestock management: from resource sufficiency to functional integrity. Cardère éditeur: France, 2011. p. 73-83.

NESKE, Márcio Zamboni. Estilos de agricultura e dinâmicas locais de desenvolvimento rural: o caso da Pecuária Familiar no Territótio Alto Camaquã do Rio Grande do Sul.2009. 207f.Dissertação (Mestrado em Desenvolvimento Rural). Programa de Pós-Graduação em Desenvolvimento Rural, Universidade Federal do Rio Grande do Sul, Porto Alegre, 2009.

OVERBECK, Gerhard Ernst et al. Os Campos Sulinos: um bioma negligenciado. In: PILLAR, Valério De Patta; MÜLLER, Sandra Cristina; CASTILHOS, Zélia Maria de Souza; JACQUES, Aino Victor Ávila. (Org.). Campos Sulinos - conservação e uso sustentável da biodiversidade. Brasília: Ministério do Meio Ambiente, 2009. p. 26-41.

PESAVENTO, Sandra Jatahy. História do Rio Grande do Sul. 4. ed., Porto Alegre: Mercado Aberto, 1985.142 p. (Série Revisão, 1).

PORTO, Marcelo Firpo; SOARES, Wagner Lopes. Modelo de desenvolvimento, agrotóxicos e saúde: um panorama da realidade agrícola brasileira e propostas para uma agenda de pesquisa inovadora. Revista Brasileira Saúde Ocupacional, São Paulo, v. 37, n. 125, p. 17-50, jan./jun. 2012.

PORTO, Rafael Gastal. Caracterização da pecuária familiar na região da Campanha Meridional: estudo de caso no município de Bagé, Rio Grande do Sul. 2008. 166 f. Dissertação (Mestrado em Sistemas de Produção Agrícola Familiar). Programa de PósGraduação em Sistemas de Produção Agrícola Familiar, Universidade Federal de Pelotas, Pelotas, 2008.

PROBIO - Cobertura vegetal do Bioma Pampa. Relatório Técnico. Porto Alegre: UFRGS e EMBRAPA Clima Temperado e Pecuária Sul, 2007.31 p.

PROGRAMA DAS NAÇÕES UNIDAS PARA O DESENVOLVIMENTO - PNUD. Atlas de Desenvolvimento Humano. 2000. Disponível em: <http://www.pnud.org.br/ atlas/>. Acesso em: 20 jun. 2011.

PROGRAMA DAS NAÇÕES UNIDAS PARA O DESENVOLVIMENTO - PNUD. Atlas de Desenvolvimento Humano. 2003. Disponível em: <http://www.pnud.org.br/ 
atlas/>. Acesso em: 20 jun. 2011.

PROGRAMA DAS NAÇÕES UNIDAS PARA O DESENVOLVIMENTO PNUD. Monitoramento do Desmatamento nos Biomas Brasileiros por Satélite. 2008. Disponível em: <http://www.pnud.org.br/meio_ambiente/reportagens/index. php?id01=3523\&lay=mam>. Acesso em: 20 jun. 2011.

REVERBEL, Carlos. O gaúcho. Aspectos de sua formação no Rio Grande e no Rio da Prata. Porto Alegre: L\&PM, 1986.109 p.

RIBEIRO, Claudio Marques. Estudo do modo de vida dos pecuaristas familiares da região da campanha do Rio Grande do Sul. 2009. 304 f. Tese (Doutorado em Desenvolvimento Rural). Programa de Pós-Graduação em Desenvolvimento Rural, Universidade Federal do Rio Grande do Sul, Porto Alegre, 2009.

SANDRINI, Gisléia Benini Duarte. Processo de inserção dos pecuaristas familiares do Rio Grande do Sul na cadeia produtiva da carne. 2005. 178 f. Dissertação (Mestrado em Desenvolvimento Rural) - Programa de Pós-Graduação em Desenvolvimento Rural, Universidade Federal do Rio Grande do Sul, Porto Alegre, 2005.

SUERTEGARAY, Dirce Maria Antunes; PIRES DA SILVA, Luís Alberto. Tchê Pampa: histórias da natureza gaúcha. In: PILLAR, Valério De Patta; MÜLLER, Sandra C.; CASTILHOS, Zélia M. S.; JACQUES, Aino Victor Ávila. (Org.). Campos Sulinos conservação e uso sustentável da biodiversidade. Brasília: Ministério do Meio Ambiente, 2009. p. 42-59.

VERDUM, Roberto. Depressão periférica e planalto. Potencial ecológico e utilização social da natureza. In: VERDUM, Roberto; BASSO, Luís A.; SUERTEGARAY, Dirce M. A (Org.). Rio Grande do Sul: paisagens e territórios em transformação. Porto Alegre: Editora da UFRGS, 2004. p. 39-60.

VERDUM, Roberto; BASSO, Luís Alberto; SUERTEGARAY, Dirce Maria Antunes (Org.). Rio Grande do Sul: paisagens e territórios em transformação. Porto Alegre: Editora da UFRGS, 2004.

WAQUIL, Paulo Dabdab et al. Vulnerability of family livestock farming in Brazil and Uruguay: a comparative analysis in the Livramento-Rivera border. In: INTERNATIONAL RANGELAND CONGRESS, 9., 2011, Rosario. Anais... Rosario, AR, 2011. p. 1-10. 1 CD-ROM.

WESZ JR., Valdemar João. Strategies and hybrid dynamics of soy transnational companies in the Southern Cone. The Journal of Peasant Studies, v. 43, n. 2, p. 286-312, mar. 2016.

WIEDERSPAHN, Henrique Oscar. A colonização Açoriana no Rio Grande do Sul. Coleção Caravela, n. 2, Porto Alegre, Escola Superior de Teologia São Lourenço de Brindes, Instituto Cultural Português, 1979. 